\title{
Projeto ponto de partida: o ensino de projetos de rodovias através de uma abordagem lúdico-real- didática
}

\author{
Daniel Sergio Presta García ${ }^{1}$, Christine Tessele Nodari², João Fortini Albano ${ }^{3}$, \\ Marcelo André Wandscheer ${ }^{4}$, Fernando Fraga de Freitas dos Santos ${ }^{5}$, César Luís Andriola 6 , \\ Cristhiane Paludo Demore ${ }^{7}$, Tiago Kirsch Lanes ${ }^{8}$
}

1Universidade Federal do Rio Grande do Sul, daniel.garcia@ufrgs.br 2Universidade Federal do Rio Grande do Sul, piti@producao.ufrgs.br 3Universidade Federal do Rio Grande do Sul, joao.albano@ufrgs.br ${ }^{4}$ CIENGE - Consultoria em Informática e Engenharia Ltda., marcelo@cienge.com.br ${ }^{5}$ CIENGE - Consultoria em Informática e Engenharia Ltda., fernando@cienge.com.br 6Universidade Federal do Rio Grande do Sul, andriola.cesar@gmail.com 7Universidade Federal do Rio Grande do Sul, cristhianedemore@gmail.com 8Universidade Federal do Rio Grande do Sul, tiagokirschlanes@gmail.com

\section{Recebido:}

16 de fevereiro de 2017

Aceito para publicação:

05 de julho de 2017

Publicado:

29 de outubro de 2017

Editor de área:

Flavio Cunto

\section{Palavras-chaves:}

Rodovias,

Projeto,

Jogos Educacional,

Indicadores de Desempenho,

AHP.

\section{Keywords:}

Highway,

Project,

Educational Games,

Key Performance Indicators,

AHP (Analytic Hierarchy Process).

\begin{abstract}
RESUMO
O ensino tradicional, baseado exclusivamente em aulas expositivas, vem transformando os alunos em meros expectadores do processo ensino-aprendizagem. Atividades lúdicodidáticas são usuais na educação infantil, mas ainda raras no ensino superior. O presente artigo propõe uma abordagem lúdico-real-didática para a disciplina de Rodovias da Universidade Federal do Rio Grande do Sul - UFRGS -, denominada de Projeto Ponto de Partida. Neste são tratados aspectos de forma, de conteúdo, de etapas e de avaliação do Projeto sob a ótica de proposta pedagógica no ensino de engenharia.
\end{abstract}

\section{ABSTRACT}

The traditional teaching, based exclusively in expository lectures, transforms students in mere spectators of the teaching-learning process. Didactic and ludic activities are usual in children's education, however still rare in higher education. This paper proposes a real didactic and ludic approach for the Highways course at the Federal University of Rio Grande do Sul - UFRGS -, named Starting Point Project. It also treats method, content, stages and evaluation aspects of the Project under the perspective of pedagogical propsal in engineering education.

DOI:10.14295/transportes.v25i3.1327
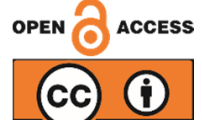

\section{INTRODUÇÃO}

A atividade de ensino tradicional, baseada exclusivamente em aulas expositivas, vem transformando os alunos em meros expectadores do processo ensino-aprendizagem (Belhot et al., 2001). No sentido inver- 
so, a utilização de jogos educacionais vem assumindo um papel de destaque em disciplinas de graduação, no Brasil e no mundo (Savi e Ulbricht, 2008), como atividade propulsora deste processo (Prensky, 2001; Garris et al., 2002). 0 conhecimento, como resultante da interação aluno com ambiente, está na base do construtivismo (Macedo, 2002; Goulart, 2004; Moretto, 2006). Na aprendizagem lúdica a transmissão de conhecimentos dá-se pelo processo de elaboração de situações didático-pedagógicas que facilitam a aprendizagem e não pela transmissão de 'verdades prontas' (Moretto, 2006).

A utilização de jogos com cenários planejados teve origem no meio militar (Van der Heijden, 1996; Schoemaker, 1993). Com o advento de novas mídias e com o acesso a novas tecnologias, a utilização de ambientes lúdicos tornou-se mais fácil de ser implementado, contudo o lúdico continua, geralmente, associado à educação infantil, sendo raras as iniciativas registradas no ensino superior. Embora ainda pouco utilizadas, algumas abordagens lúdicas são empregadas em instituições de ensino superior e, em particular, em alguns cursos de engenharia. Um case de sucesso refere-se às competições de Pontes de Espaguete (González et al. 2005). Esse modelo de competição, inicialmente realizada em 1983, em Okanagan College, na Colúmbia Britânica, Canadá, popularizou-se e foi adotado por diversas instituições de ensino superior em todo o mundo.

No Brasil, a Universidade Federal do Rio Grande do Sul foi pioneira na competição, tendo realizado sua primeira edição em 2004, detendo também o recorde nacional (234 kgf). Outros exemplos de atividades lúdicas que fazem parte do currículo de disciplinas de Engenharia Civil e de Produção de algumas instituições de ensino superior são a Fábrica de Casas Lego, o Jogo do Abajur e o LEAPCON (Ozelkan $e$ Galambosi, 2007; Sacks et al., 2007). Entre os objetivos dessas atividades está a comparação das diferenças existentes entre os métodos de produção e a comparação de desempenho entre a construção convencional e enxuta.

A disciplina de Rodovias da Universidade Federal do Rio Grande do Sul oferece o primeiro contado do estudante de Engenharia Civil da UFRGS com a área de transportes. Com caráter teórico-prático, ela prioriza a formação científica e profissional dos alunos nas áreas de Projeto Geométrico e de Terraplenagem (García e Albano, 2004). Uma particularidade relevante da disciplina decorre da proposição de um trabalho de projeto de um segmento rodoviário com características bastante próximas das desenvolvidas por empresas e profissionais que atuam no mercado.

Este artigo descreve a estrutura do projeto de ensino/aprendizagem, em um ambiente lúdico-realdidático, desenvolvido na disciplina de Rodovias da UFRGS denominado "Ponto de Partida". Busca-se também apresentar um método de avaliação para o Projeto e os resultados de sua primeira edição.

\section{O PROJETO PONTO DE PARTIDA}

O Projeto Ponto de Partida é um dos projetos que integra o Programa de Desenvolvimento Tecnológico em Infraestrutura de Transportes - ProINFRA -, do Laboratório de Sistemas de Transportes (LASTRAN), da Universidade Federal do Rio Grande do Sul - UFRGS. O Projeto visa proporcionar aos alunos de graduação um ambiente lúdico-real-didático para formação e qualificação no seu primeiro contato com uma disciplina de transportes.

\subsection{Objetivos}

O objetivo principal do Projeto Ponto de Partida é oferecer ao aluno de graduação da disciplina de rodovias a possibilidade de atuar como engenheiro (coordenando, realizando estudos e projetos e fiscalizando) em um ambiente lúdico-real-didático, onde uma pequena parte dos seus colegas formam sua equipe e todos os demais são seus concorrentes. Neste formato, o aluno e a equipe são avaliados por uma série de quesitos (melhor estudo apresentado em audiência pública, melhor projeto segundo indicadores de desempenho definidos, melhor análise das propostas concorrentes, etc.) e confrontados com seus pares.

A formação ampla do aluno de graduação de engenharia é um objetivo secundário do Projeto. Ao 
disponibilizar recursos e desafios ao aluno, que permitam seu crescimento como profissional e cidadão, pretende-se ampliar suas habilidades de: (i) liderança, (ii) coordenação, (iii) desenvolvimento tecnológico e (iv) resiliência (capacidade do indivíduo em lidar com problemas, superar obstáculos e resistir à pressão em situações adversas).

Para poder atingir os objetivos mencionados, o Projeto foi concebido de forma a ser replicável ao longo do tempo e em outras instituições de ensino. Esta característica do Projeto contempla o objetivo maior do mesmo (macro): oferecer às disciplinas de graduação de rodovias de universidades brasileiras uma atividade de projeto lúdico-real-didática, com viabilidade de implantação e com modelo de avaliação definido.

\subsection{Etapas do Projeto}

O Projeto foi concebido de forma a simular atividades desenvolvidas por engenheiros em projetos de infraestrutura de transportes. 0 trabalho desenvolvido pelos alunos, em equipes, simula vários dos procedimentos comuns a uma Concorrência Pública. De forma a garantir o aprimoramento contínuo das edições sucessivas do Projeto, as etapas foram agrupadas segundo a ferramenta de gestão de quatro passos do Ciclo PDCA (Figura 1).

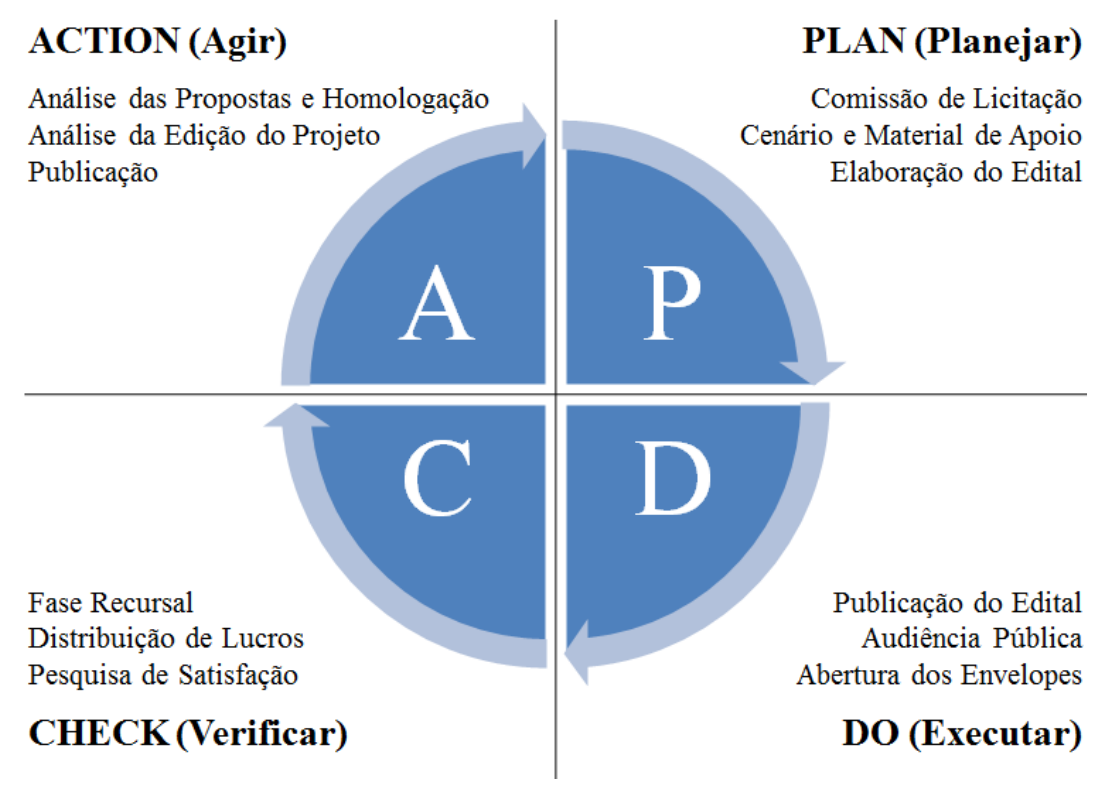

Figura 1: Ciclo PDCA do Projeto Ponto de Partida

A escolha por agrupar as etapas em um Ciclo PDCA decorre do entendimento do conceito do processo na gestão do conhecimento gerado em cada edição do Projeto conforme preconizado por Walasek et al. (2011). Na sequência, as etapas são apresentadas em destaque.

\subsubsection{Planejar: Comissão de Licitação}

Cada edição do Projeto Ponto de Partida tem por etapa inicial o planejamento da Comissão de Licitação. Esta deve ser formada pelo seu presidente (geralmente o professor da disciplina), membros avaliadores (denominados de Banca Examinadora - professores, pesquisadores e profissionais da área convidados) e equipe de apoio (denominados de Fiscais - monitores e bolsistas).

Esta etapa tem por finalidade principal a construção de um grupo de trabalho com duas características fundamentais: (i) engajamento no Projeto - permitindo o desenvolvimento do mesmo sem quebra de continuidade e (ii) reconhecida excelência - de forma a viabilizar análises qualificadas nas diferentes etapas do Projeto. 


\subsubsection{Planejar: Cenário e Material de Apoio}

O cenário real-didático deve ser planejado para oferecer informações reais (contextualização) sem prejudicar o processo de ensino-aprendizagem (didático). Nesse contexto, optou-se por utilizar bases de dados reais em sistemas GIS (Geographic Information Systems) com a identificação do relevo, hidrografia, sistema viário existente, ocupação do solo e demais condicionantes (Figura 2). Os arquivos devem conter os elementos necessários para o desenvolvimento de estudos e projetos condizentes com a classe da rodovia que irão integrar o Termo de Referência.

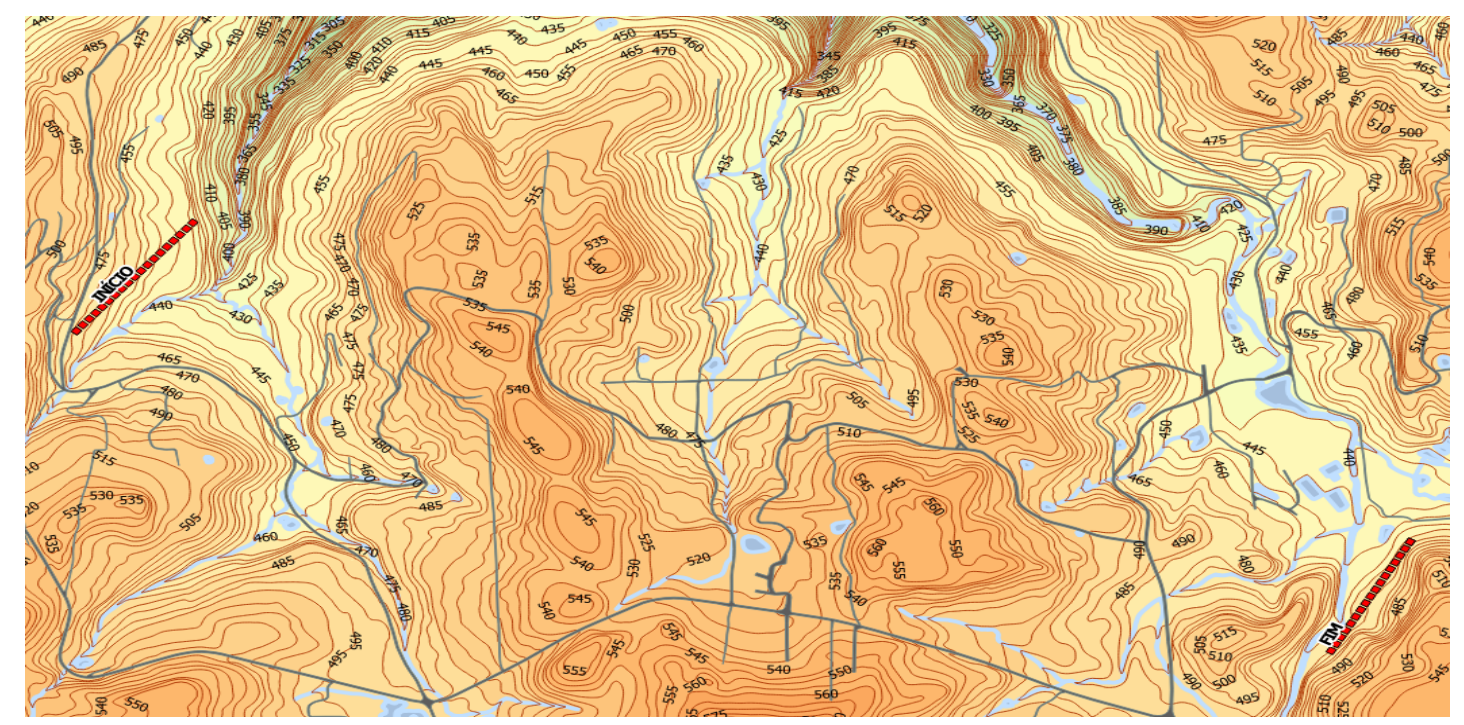

Figura 2: recorte de imagem georreferenciada disponibilizada na Edição UFRGS 2016/1
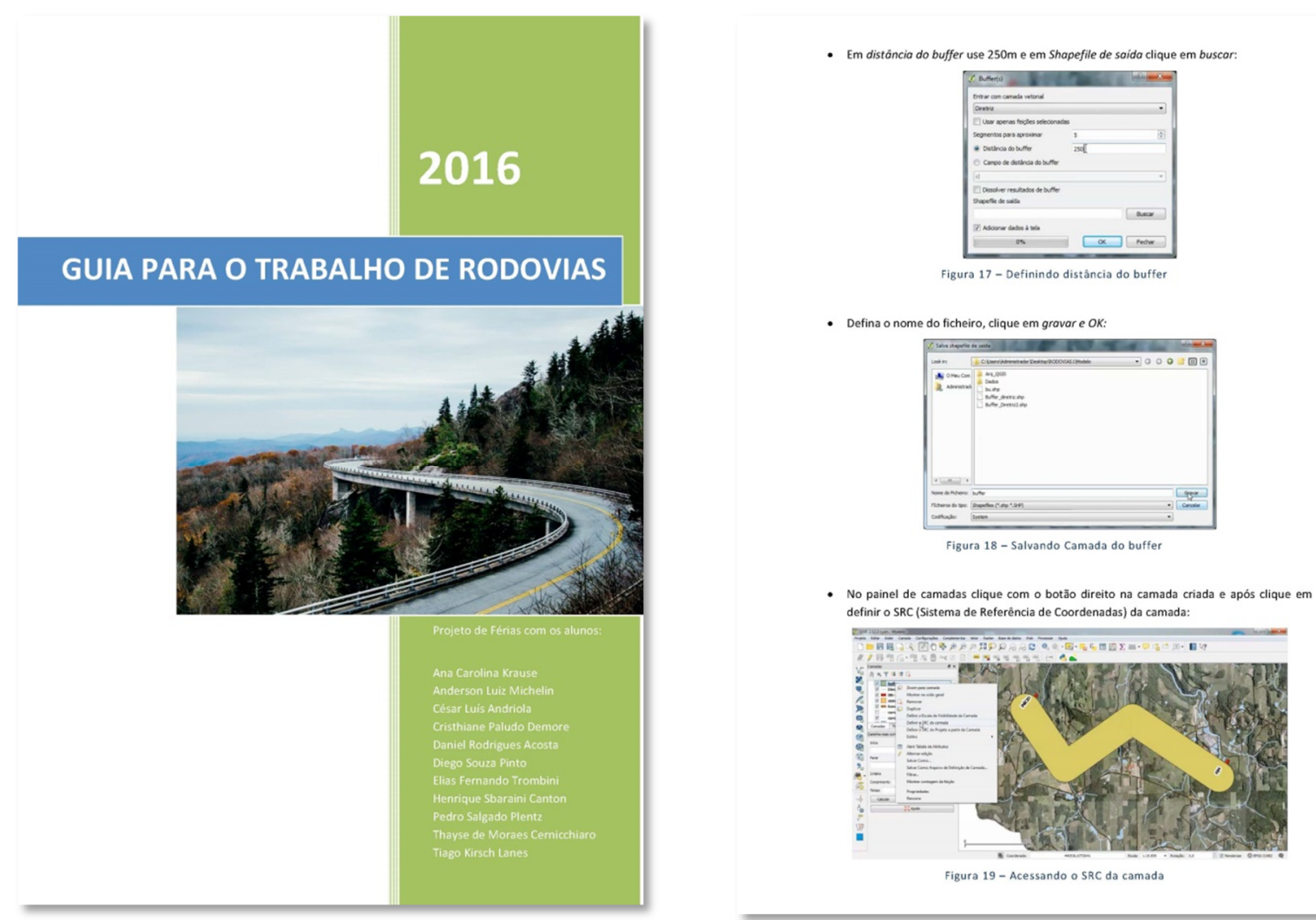

Figura 3: Material didático disponibilizado para capacitação dos alunos 
Os alunos, além do conhecimento exigido e avaliado de estudos de traçado, projeto geométrico e de terraplenagem, deverão estar aptos para a utilização de softwares GIS e de Projetos Viários. De forma a facilitar o processo de capacitação dos alunos nas 'ferramentas' necessárias ao trabalho, é planejado o material de apoio a ser disponibilizado (guias passo-a-passo em formato .PDF - Figura 3 - e tutoriais em vídeo).

\subsubsection{Planejar: Elaboração do Edital}

O instrumento pelo qual uma administração torna pública a realização de uma Licitação é o Edital. Integra o Edital, além dos arquivos já mencionados, o Termo de Referência que apresenta instruções quanto às atividades a serem desenvolvidas, o cenário real-didático e as especificações técnicas de norma a serem utilizadas. Os principais parâmetros de projeto (norma técnica utilizada, classe da rodovia e região), bem como os formatos de encaminhamento do projeto, estão discriminados neste documento inicial.

\subsubsection{Executar: Publicação do Edital}

O início dos trabalhos do Projeto, para os alunos, ocorre no início do semestre (primeira ou segunda semana de aula) com a formação das equipes, geralmente, de quatro ou três integrantes e com o recebimento/apresentação do Edital. Devidamente notificados pelo Edital quanto às exigências dos prazos, dos formatos, dos eventos e das condicionantes do projeto, é dado um cronograma planejado às equipes que, posteriormente, será confrontado com o realizado.

\subsubsection{Executar: Audiência Pública}

A etapa de Audiência Pública aborda os Estudos de Viabilidade Técnica, Econômica e Ambiental - EVTEA - para implantação de trecho rodoviário. A atividade, que corresponde a $20 \%$ da nota total, é desenvolvida em sala de aula com as equipes apresentando seus estudos para as demais equipes e para Banca Examinadora (Figura 4b). Ao término da Audiência Pública, cada equipe tem a sua alternativa de traçado escolhida, determinando a faixa de exploração a ser utilizada na etapa de projeto (Figura 4a). Qualquer alteração desta faixa nas etapas subsequentes irá produzir penalizações à equipe.

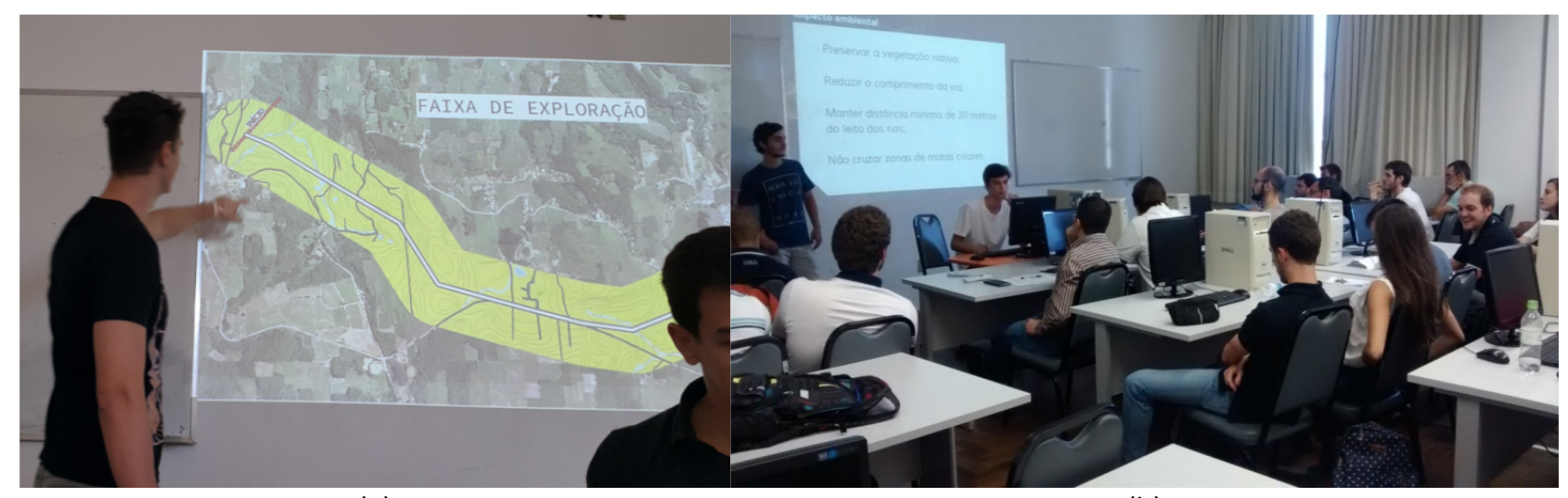

(a)

(b)

Figura 4: equipes apresentando EVTEA em Audiência Pública

\subsubsection{Executar: Abertura dos Envelopes}

Entre a Audiência Pública e a etapa de Abertura dos Envelopes desenvolve-se o projeto geométrico e de terraplenagem (oito semanas). Nessa etapa, as equipes devem definir o eixo planimétrico, projeto altimétrico e seções transversais de projeto. A utilização de um software para auxílio ao projeto favorece a possibilidade de otimização do o mesmo, realizando ajustes e correções, de forma a obter o melhor projeto possível (Figura 5).

O Projeto de Terraplenagem, decorrente do corpo estradal definido na etapa do Projeto Geométrico, é um projeto simplificado. Na edição 2016/1, o material proveniente de corte foi totalmente classificado 
como de 1 a Categoria com condições de suporte para terraplenagem e fator de homogeneização de 1,3. Os custos da terraplenagem são calculados a partir de valores reais disponibilizados pelo Sistema de Custos Rodoviários do DNIT (SICRO2).

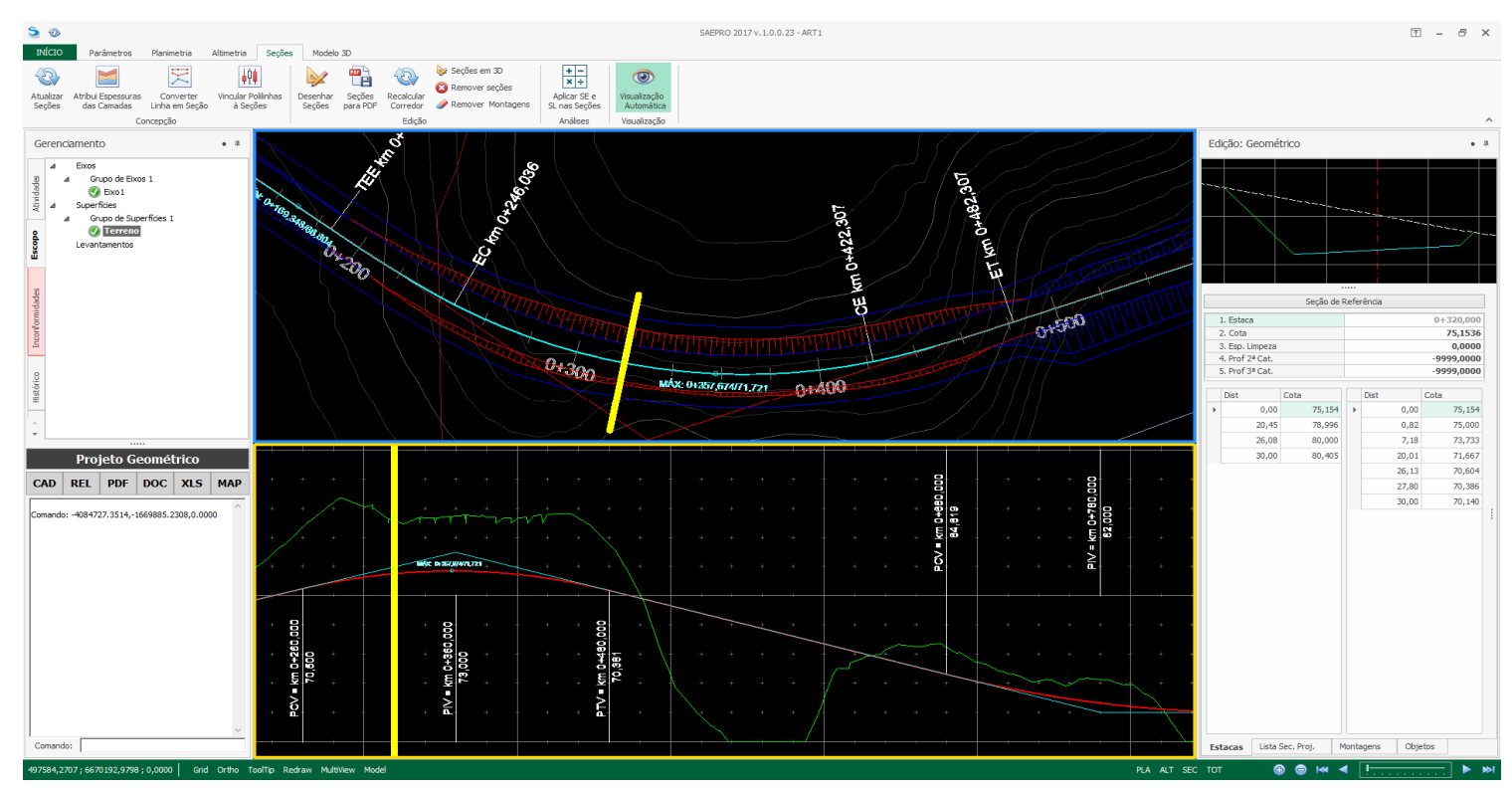

Figura 5: Exemplo de projeto geométrico realizado na disciplina no software SAEPRO

A Abertura dos Envelopes ocorre em evento único em sala de aula. As equipes devem encaminhar, em envelope pardo lacrado, os documentos: (i) Relatório de Projeto em formato A4, (ii) Projeto Executivo em formato A3, (iii) Proposta Técnica e de Preço (A4) e (iv) mídia (DVD) com cópia em formato PDF dos documentos do projeto. Na Proposta Técnica e de Preço constam os indicadores de desempenho adotados. Na edição 2016/1 foram considerados como indicadores de desempenho: (i) tortuosidade média, (ii) comprimento virtual e (iii) custo final dos serviços de terraplenagem. Na abertura das propostas, os indicadores são registrados em planilha específica com o objetivo de caracterizar a distribuição dos valores, média, desvio padrão e o posicionamento de cada equipe. Os indicadores permitem identificar as melhores configurações de projeto, sendo estes avaliados em até $20 \%$ da nota total.

\subsubsection{Verificar: Fase Recursal}

Os indicadores de desempenho das equipes são valores autodeclarados, ou seja, estão sujeitos a não corresponder com os valores oriundos do projeto. Nesse sentido, a etapa que dá sequência à Abertura dos Envelopes é a Fase Recursal. Nesta etapa, cada equipe deve analisar duas propostas concorrentes (por sorteio) dispondo, para tanto, de 30 minutos por proposta. Da análise realizada por cada equipe resulta documento a ser anexado à ata do Edital, onde as equipes tentarão desqualificar as propostas concorrentes mediante a identificação de problemas de cálculo, valores fora de norma, atividades não realizadas, etc. A atividade Fase Recursal corresponde a $10 \%$ da nota total. 0 confronto de análises de diferentes equipes com a análise desenvolvida pelos membros da Banca Examinadora irá indicar a nota da equipe neste quesito, bem como possíveis penalizações às equipes que cometeram erros grosseiros.

\subsubsection{Verificar: Distribuição de Lucros}

Uma crítica muito comum por parte dos alunos aos trabalhos em grupo decorre da diferença de comprometimento entre os membros. De forma a propiciar uma autoavaliação do indivíduo e do grupo, a etapa Distribuição dos Lucros permite a diferenciação de nota entre os membros de uma mesma equipe com um delta de até 1 ponto. Este exercício de autocrítica e de relacionamento interpessoal é pouco tratado nas atividades acadêmicas. A reflexão sobre este tema gera o amadurecimento do indivíduo 
como profissional, sendo relevante à proposta do Projeto. A negociação dos valores, conforme participação, é interna à equipe, autodeclarada e consensual, por meio da assinatura do Termo de Distribuição de Lucros.

\subsubsection{Verificar: Pesquisa de Satisfação}

A Pesquisa de Satisfação é a etapa que encerra a participação dos alunos no Projeto. É nesta etapa que o aluno tem a possibilidade de avaliar o Projeto Ponto de Partida segundo os critérios a serem tratados no tópico Metodologia de Avaliação.

\subsubsection{Agir: Análise das Propostas e Homologação}

A Análise das Propostas e Homologação é a etapa que inaugura o passo Agir do ciclo PDCA do Projeto. Esta etapa é desenvolvida pela Comissão de Licitação que, inicialmente, analisa os recursos encaminhados pelas equipes concorrentes. A pontuação de até $10 \%$ da nota total do trabalho sobre a etapa de Fase Recursal é atribuída pela Comissão de Licitação em função da capacidade verificada na equipe fiscalizadora em identificar problemas existentes nas propostas concorrentes.

As equipes fiscalizadas que apresentarem problemas no projeto, com possibilidade de alteração dos indicadores de desempenho utilizados para elaboração da Proposta Técnica e de Preços, poderão ser penalizadas com acréscimo de valores percentuais sobre o custo total da terraplenagem. Em caso de erros graves repetidos, a Comissão de Licitação poderá desqualificar a equipe zerando a pontuação na etapa de Abertura dos Envelopes.

Uma vez tendo-se computado os $20 \%$ da etapa de Audiência Pública, os $20 \%$ da etapa da Abertura dos Envelopes e os 10\% da etapa Fase Recursal, é iniciada a avaliação da Proposta encaminhada pela equipe como trabalho didático. Esta avaliação considera aspectos de precisão, de forma, de português, de conteúdos presentes e de outros tantos critérios utilizados na correção de trabalhos didáticos. Tal item equivale a $50 \%$ da nota total do trabalho.

\subsubsection{Agir: Análise da Edição do Projeto}

A Comissão de Licitação, de posse dos apontamentos registrados ao longo de todas as etapas desenvolvidas no projeto, das avaliações finais das equipes e dos dados da pesquisa de satisfação dos alunos, desenvolve, nesta etapa, a análise da Edição do Projeto. Aspectos positivos e negativos identificados devem ser registrados como novas orientações para o conjunto de 'boas práticas' a serem retomadas nas etapas de Planejamento da Edição posterior.

\subsubsection{Agir: Publicação}

De forma a oferecer subsídios a edições futuras do Projeto e consolidar a produção intelectual desenvolvida por todos os agentes envolvidos, cada Edição será considerada concluída quando da publicação da mesma. Por meio de uma atividade de extensão, alunos voluntários oriundos do projeto, participaram da produção/publicação, em formato $e B o o k$, da produção intelectual produzida no projeto. Tal produção permitiu apropriar autoria de capítulo tanto aos alunos participantes (através de Contrato de Cessão de Direitos Autorais e Publicações), como à Banca Examinadora. Reunir e disponibilizar as publicações das edições do Projeto em um meio eletrônico/digital de fácil acesso é a principal contribuição para as edições subsequentes.

\subsection{Recursos Necessários}

De forma a viabilizar acesso a softwares que não demandem investimento financeiro, por parte das instituições que desejarem replicar o Projeto Ponto de Partida, são recomendadas as seguintes ferramentas computacionais:

- QGIS: software GIS (Open Source), que permite a manipulação do cenário georreferenciado. A utilização é gratuita e disponibilizada em http://www.qgis.org/en/site/; 
- SAEPRO: Sistema Avançado para Estudos e Projetos Viários. Software desenvolvido pelas empresas STE - Serviços Técnicos de Engenharia S.A. - e CIENGE - Consultoria em Informática e Engenharia Ltda. - em parceria com a UFRGS (García et al., 2014). A versão acadêmica requer o cadastro da instituição através do site http://www.stesa.com.br/.

o Edital contendo o Cenário, o Termo de Referência e o material de apoio (apostila, guias passo-apasso, tutoriais e templates) é disponibilizado no site http://www.ufrgs.br/saepro/ppp. As instituições que desejarem aplicar o Projeto Ponto de Partida poderão: (i) utilizar este material, (ii) desenvolver seus próprios conteúdos ou (iii) vincular-se a uma atividade coordenada, interinstitucional, de construção e ampliação de materiais didáticos para este fim.

\section{METODOLOGIA DE AVALIAÇÃO DE JOGOS EDUCACIONAIS}

A proposta de um projeto com abordagem lúdico-real-didática requer uma metodologia de análise e avaliação. No Projeto Ponto de Partida são utilizados dois métodos de avaliação: (i) grupos focais para a avaliação dos professores, pesquisadores e profissionais que atuam na área e (ii) pesquisa de satisfação aplicada sobre os alunos participantes.

\subsection{Grupos Focais}

Grupo focal é um método de pesquisa qualitativa, que se baseia em grupos de discussão que dialogam sobre um tópico específico, com objetivo de obter informações detalhadas sobre o mesmo. Morgan (1996) define grupos focais como uma técnica de pesquisa qualitativa, derivada das entrevistas grupais, que coleta informações por meio das interações grupais. Segundo Krueger e Casey (2014), os grupos focais são formados por grupos pequenos de pessoas, com características comuns e com o objetivo de fornecer informações de forma a produzir o entendimento de um tópico de interesse. 0 envolvimento das pessoas, no grupo focal, produz uma maior riqueza de informações qualitativas, se comparado a entrevistas individuais.

No Projeto existem dois momentos distintos onde a técnica de grupo focal é empregada. Os grupos focais são fundamentais na concepção do cenário da atividade lúdica proposta (fase Planejar) e, ao término, na análise das atividades desenvolvidas (fase Agir), prestando-se como base de referência para edições futuras do projeto.

\subsection{Pesquisa de Satisfação}

A avaliação do Projeto Ponto de Partida pelos alunos utiliza uma Pesquisa de Satisfação ao término das atividades. A construção do formulário utilizou um conjunto de modelos empregados na avaliação de jogos educacionais, apresentados a seguir.

\subsubsection{Avaliação de treinamentos pelo modelo de Kirkpatrick}

Kirkpatrick (1994) sugere um modelo para avaliar a efetividade de programas de treinamento conhecido como "os quatro níveis": (i) reação - o que os participantes pensam e sentem sobre a formação, (ii) aprendizagem - os conhecimentos e competências que os participantes adquiriram graças à formação, (iii) comportamento - conhecimentos e competências efetivamente retidos e aplicados e (iv) resultados - melhorias no desempenho resultantes do uso regular dos novos conhecimentos e competências. Os quatro níveis seguem uma sequência de avaliação, em que a reação é fundamentalmente o primeiro nível a ser avaliado, visto que, mesmo se a reação dos participantes for positiva e satisfatória, não se pode garantir o aprendizado, no entanto se a reação dos participantes for negativa e insatisfatória, a possibilidade de aprendizado é reduzida, pois provavelmente não estarão motivados a aprender. 0 Projeto Ponto de Partida pretende avaliar este nível por meio de um questionário de satisfação (Kirkpatrick, 2007) aplicado aos alunos, avaliando sua motivação, experiência e conhecimento adquirido por meio dos modelos a seguir descritos. 


\subsubsection{Avaliação da motivação pelo modelo ARCS}

O modelo ARCS, proposto por Keller (2009), considera a motivação como elemento fundamental no processo ensino-aprendizagem. 0 acrônico ARCS resulta dos termos, em inglês, das categorias consideradas relevantes no processo de motivação: (i) atenção, (ii) relevância, (iii) confiança e (iv) satisfação. Para Keller, despertar a atenção dos estudantes não é difícil, mas sustentá-la é um desafio. Mostrar relevância do que será ensinado é fator determinante e transmite a importância do que será aprendido, fazendo com que a atenção que havia sido cativada anteriormente seja reestabelecida. 0 aluno deve correlacionar o conhecimento construído aos seus objetivos pessoais, se a aprendizagem for estimulante para ele, ele estará motivado a aprender. A confiança, na teoria de Keller, ajuda os alunos perceberem e sentirem que obterão sucesso com a aprendizagem e poderão construir este sucesso (Keller, 1983). 0 Instructional Materials Motivational Scale (IMMS) é um questionário desenvolvido por Keller (2009), aplicado aos participantes, após a utilização do material educacional que se deseja avaliar. O Projeto Ponto de Partida incorpora tal questionário na sua pesquisa de avaliação.

Tabela 1. Síntese das questões para avaliação do Projeto Ponto de Partida

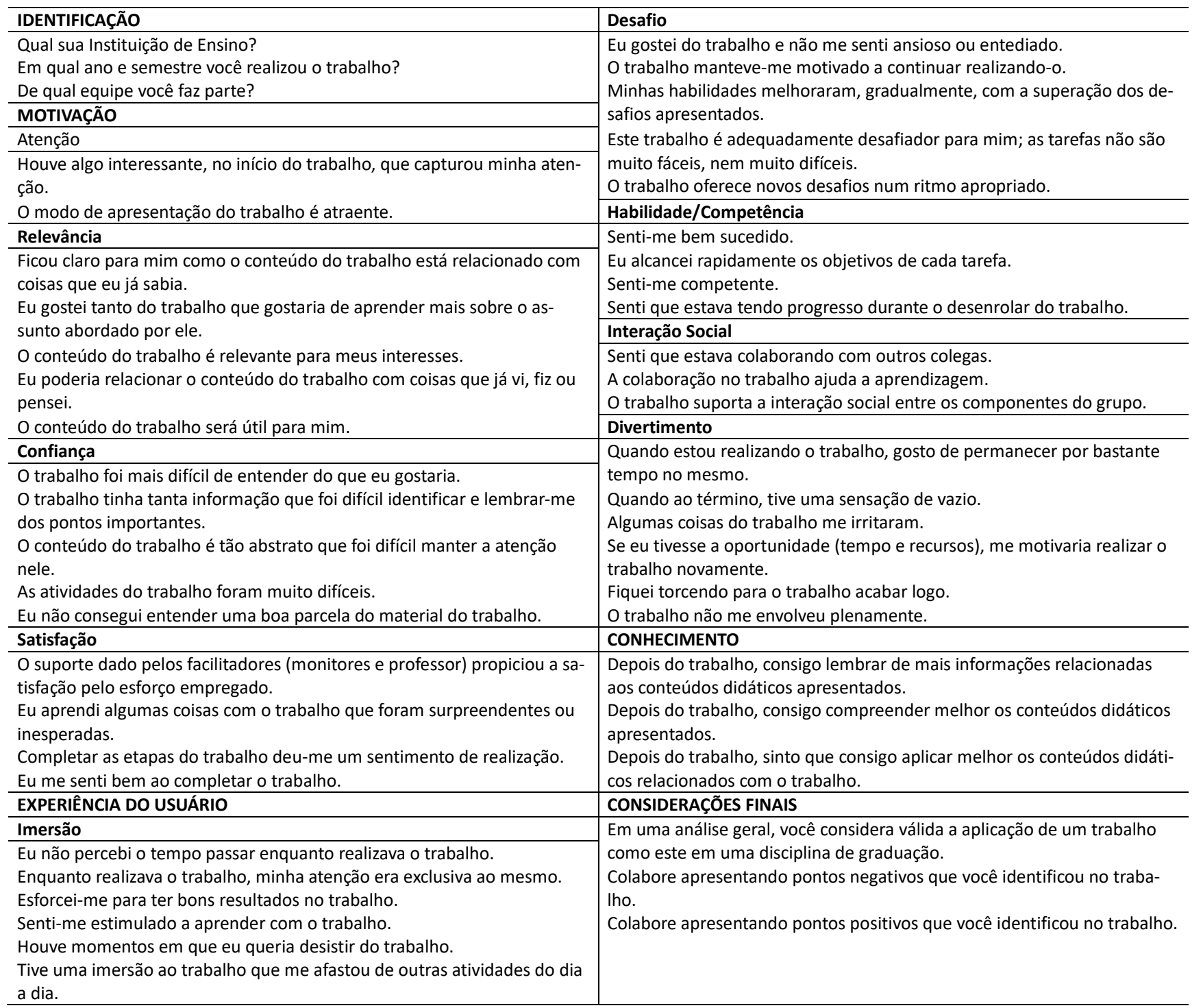

\subsubsection{Avaliação da experiência do usuário pelo modelo UX}

A experiência do usuário (User eXperience - UX) avalia a percepção das pessoas sobre a utilização de um produto, sistema ou serviço (Takatalo et al., 2010). Na área de jogos educacionais, a maioria dos modelos 
de UX utilizam como critérios de avaliação os conceitos: (i) imersão, (ii) desafio, (iii) habilidade, (iv) competência, (v) interação social e (vi) divertimento. Tais critérios são utilizados na Pesquisa de Satisfação do Projeto.

\subsubsection{Avaliação do conhecimento adquirido segundo a taxonomia de Bloom}

A Taxonomia de Bloom classifica metas e objetivos ligados ao desenvolvimento educacional em três domínios: (i) cognitivo, (ii) afetivo e (iii) psicomotor (Bloom, 1956). 0 domínio mais conhecido e difundido atualmente é o cognitivo. Ele contempla atitudes, competências e processos de aquisição de conhecimento, a fim de facilitar o planejamento do ensino e da aprendizagem. 0 conhecimento pode ser descrito em seis categorias distintas: (i) conhecimento, (ii) compreensão, (iii) aplicação, (iv) análise, (v) síntese e (vi) avaliação. Esta estrutura é aplicada para planejar e avaliar a efetividade da aprendizagem. No modelo proposto, na presente pesquisa, são considerados apenas os três primeiros níveis.

A Tabela 1 apresenta síntese das questões do formulário de pesquisa de satisfação do Projeto, conforme modelo ARCS, UX e Bloom. Tais questões utilizam para resposta uma escala Likert de 7 pontos. Foram inseridas questões de identificação e considerações finais.

\section{ANÁLISE DOS RESULTADOS}

Os resultados, a seguir analisados, referem-se a 1a Edição do Projeto Ponto de Partida realizada na UFRGS entre 02 de março e 07 de julho de 2016 (PPP - UFRGS - 2016/1). A proposta de análise para o Projeto é dividida entre a percepção do professor, dos pesquisadores e dos profissionais da área que atuaram como Comissão de Licitação e dos alunos.

\subsection{Avaliação dos Professores, Pesquisadores e Profissionais da Área}

A utilização de Grupo Focal ocorre, no Projeto Ponto de Partida, em duas etapas distintas: (i) na formação da Comissão de Licitação (passo Planejar) e (ii) na Análise da Edição do Projeto (passo Agir), etapa esta não executada. Sua realização deve ocorrer juntamente com as etapas do passo Planejar do novo ciclo PDCA do Projeto (edição PPP - UFRGS - 2016/2).

\subsection{Avaliação dos Alunos}

A avaliação dos alunos foi obtida a partir da aplicação da Pesquisa de Satisfação, conforme questões apresentadas na Tabela 1, através de formulário de avaliação produzido na ferramenta Formulários Google do Google Drive. Foram convidados a participar os membros das 22 equipes, totalizando 85 alunos. Destes, 70 alunos responderam o questionário $(82,4 \%)$ e $41(48,2 \%)$ deram contribuições sobre aspectos positivos e negativos do Projeto por escrito.

A Tabela 2 sintetiza a avaliação dada pelos alunos ao Projeto, segundo os critérios propostos, através do percentual de avaliações positivas, neutras e negativas. 0 percentual de avaliações positivas e negativas foi dividido em três grupos para manter a paridade com a escala Likert adotada. Desta forma, temse, por exemplo, para a escala positiva: (i) levemente positiva, (ii) em grande parte positiva e (iii) fortemente positiva.

Analisando a Tabela 2 é possível observar que o Projeto Ponto de Partida conseguiu motivar os alunos participantes conforme preconiza o modelo ARCS. Merece destaque o critério Satisfação, com apenas $1,9 \%$ das avaliações classificadas como levemente negativas. Em contrapartida, foram registradas 42,6\% de avaliações negativas no critério confiança, indicando, provavelmente, que o Projeto deva dispor de material de apoio mais qualificado.

Os critérios que avaliaram a Experiência do Usuário com o Projeto também apresentaram indicadores positivos. Destaca-se, entre todos, o critério Interação Social com apenas 7,6\% de avaliações negativas. No outro extremo, pode-se afirmar que o Projeto não pode ser percebido como uma atividade que trouxesse algum grau de divertimento por $63,9 \%$ dos alunos. 
Os critérios que compõem a avaliação do conhecimento, segundo a taxonomia de Bloom, tiveram avaliações significativamente positivas. É possível destacar que os critérios Lembrar, Compreender e Aplicar foram avaliados como levemente negativos por menos de 5,0\% dos alunos. Destacam-se, também, a similaridade dos valores e as altas taxas obtidas nas classificações fortemente positiva e, em grande parte, positiva.

Tabela 2: Avaliações obtidas, por critério, para PPP - UFRGS - 2016/1

\begin{tabular}{|c|c|c|c|c|c|c|c|}
\hline \multirow{3}{*}{ Critério } & \multicolumn{7}{|c|}{ Avaliação } \\
\hline & \multicolumn{3}{|c|}{ Negativa } & \multirow[t]{2}{*}{ Neutra } & \multicolumn{3}{|c|}{ Positiva } \\
\hline & Fortemente & Grande parte & Levemente & & Levemente & Grande parte & Fortemente \\
\hline \multicolumn{8}{|l|}{ Motivação } \\
\hline Atenção & $0,0 \%$ & $2,9 \%$ & $4,3 \%$ & $7,9 \%$ & $24,3 \%$ & $39,3 \%$ & $21,4 \%$ \\
\hline Relevância & $1,4 \%$ & $1,4 \%$ & $1,8 \%$ & $14,3 \%$ & $28,1 \%$ & $27,1 \%$ & $22,9 \%$ \\
\hline Confiança & $6,6 \%$ & $15,1 \%$ & $20,6 \%$ & $14,6 \%$ & $17,1 \%$ & $15,1 \%$ & $10,9 \%$ \\
\hline Satisfação & $0,0 \%$ & $0,0 \%$ & $1,9 \%$ & $6,2 \%$ & $21,9 \%$ & $25,2 \%$ & $44,8 \%$ \\
\hline \multicolumn{8}{|l|}{ Experiência do Usuário } \\
\hline Imersão & $5,5 \%$ & $7,4 \%$ & $9,3 \%$ & $13,2 \%$ & $17,7 \%$ & $25,8 \%$ & $21,1 \%$ \\
\hline Desafio & $2,9 \%$ & $5,2 \%$ & $10,9 \%$ & $16,0 \%$ & $32,1 \%$ & $25,2 \%$ & $7,7 \%$ \\
\hline Habilidade/Competência & $2,5 \%$ & $6,4 \%$ & $10,4 \%$ & $11,1 \%$ & $25,0 \%$ & $30,4 \%$ & $14,3 \%$ \\
\hline Interação Social & $0,5 \%$ & $1,9 \%$ & $5,2 \%$ & $7,1 \%$ & $17,1 \%$ & $28,6 \%$ & $39,5 \%$ \\
\hline Divertimento & $12,6 \%$ & $15,0 \%$ & $20,5 \%$ & $15,8 \%$ & $16,2 \%$ & $11,9 \%$ & $7,9 \%$ \\
\hline \multicolumn{8}{|l|}{ Conhecimento } \\
\hline Lembrar & $0,0 \%$ & $0,0 \%$ & $4,3 \%$ & $4,3 \%$ & $18,6 \%$ & $18,6 \%$ & $32,9 \%$ \\
\hline Compreender & $0,0 \%$ & $0,0 \%$ & $2,9 \%$ & $7,1 \%$ & $17,1 \%$ & $17,1 \%$ & $37,1 \%$ \\
\hline Aplicar & $0,0 \%$ & $0,0 \%$ & $2,9 \%$ & $7,1 \%$ & $17,1 \%$ & $17,1 \%$ & $35,7 \%$ \\
\hline \multicolumn{8}{|l|}{ Considerações Finais } \\
\hline Validade & $0,0 \%$ & $2,9 \%$ & $1,4 \%$ & $1,4 \%$ & $12,9 \%$ & $27,1 \%$ & $54,3 \%$ \\
\hline
\end{tabular}

Tabela 3: frases de alunos registradas no questionário da Pesquisa de Satisfação

\begin{tabular}{l} 
NEGATIVAS \\
\hline Longa duração do mesmo. \\
\hline Muito conteúdo para estudar. \\
Algumas partes do trabalho não estão totalmente explicadas nos guias. \\
Trabalho tomava muito tempo, entre casa e monitoria. Assim, prejudi- \\
cando outras cadeiras. \\
Não ficou claro em aula como seriam realizadas algumas atividades do \\
trabalho, o que me incomodou um pouco, visto que o volume de ativida- \\
des foi bem grande.
\end{tabular}

\section{POSITIVAS}

Grande aprendizado na área de projetos.

Aprendi muito com o trabalho, tanto com relação à disciplina, quanto com relação às plataformas / aos programas utilizados.

O trabalho me fez sentir como um engenheiro.

Acredito ter sido muito importante a experiência de projetar uma rodovia em um local real, com normas reais.

Envolve muito o aluno, que se torna obrigado a entender como funciona o projeto e desenvolvimento de uma rodovia.

A última questão objetiva do questionário propunha aos alunos participantes avaliar o Projeto Ponto de Partida como uma atividade pertinente a uma disciplina de graduação. De todas as questões objetivas do questionário, foi esta que apresentou o maior índice em fortemente positiva (54,3\%). 0 índice de rejeição foi de apenas $4,3 \%$.

Além das questões a serem respondidas com uso da escala Likert, propôs-se aos alunos a contribuição, por escrito, com a indicação de aspectos considerados negativos e positivos no Projeto. A Tabela 3 reúne algumas das frases escritas pelos alunos que merecem destaque.

\section{CONCLUSÕES}

A primeira edição do Projeto Ponto de Partida demostrou ser uma iniciativa didática com notável potencial metodológico para as disciplinas de rodovias de instituições de ensino superior brasileiras. 0 Projeto 
apresenta uma formatação com etapas bem definidas e sequenciadas, ainda assim, passíveis de adequações conforme requisitos específicos (por exemplo, carga horária disponível, ou limitação de sistema os softwares podem ser open source ou licenciados). Percebe-se, portanto, a característica de replicabilidade do Projeto, sendo possível o atendimento do objetivo maior, que é o de oferecer às disciplinas de graduação de rodovias de universidades brasileiras uma atividade de projeto lúdico-real-didática, com viabilidade de implantação e com modelo de avaliação definido.

Um exemplo da replicabilidade decorre das instituições, no estado do Rio Grande do Sul, que já se beneficiam do Projeto. A Figura 7 reúne imagens de diferentes etapas do Projeto Ponto de Partida em diversas instituições de ensino superior (UFRGS, UFSM, UNIVATES, UNISC, UCS e ULBRA).
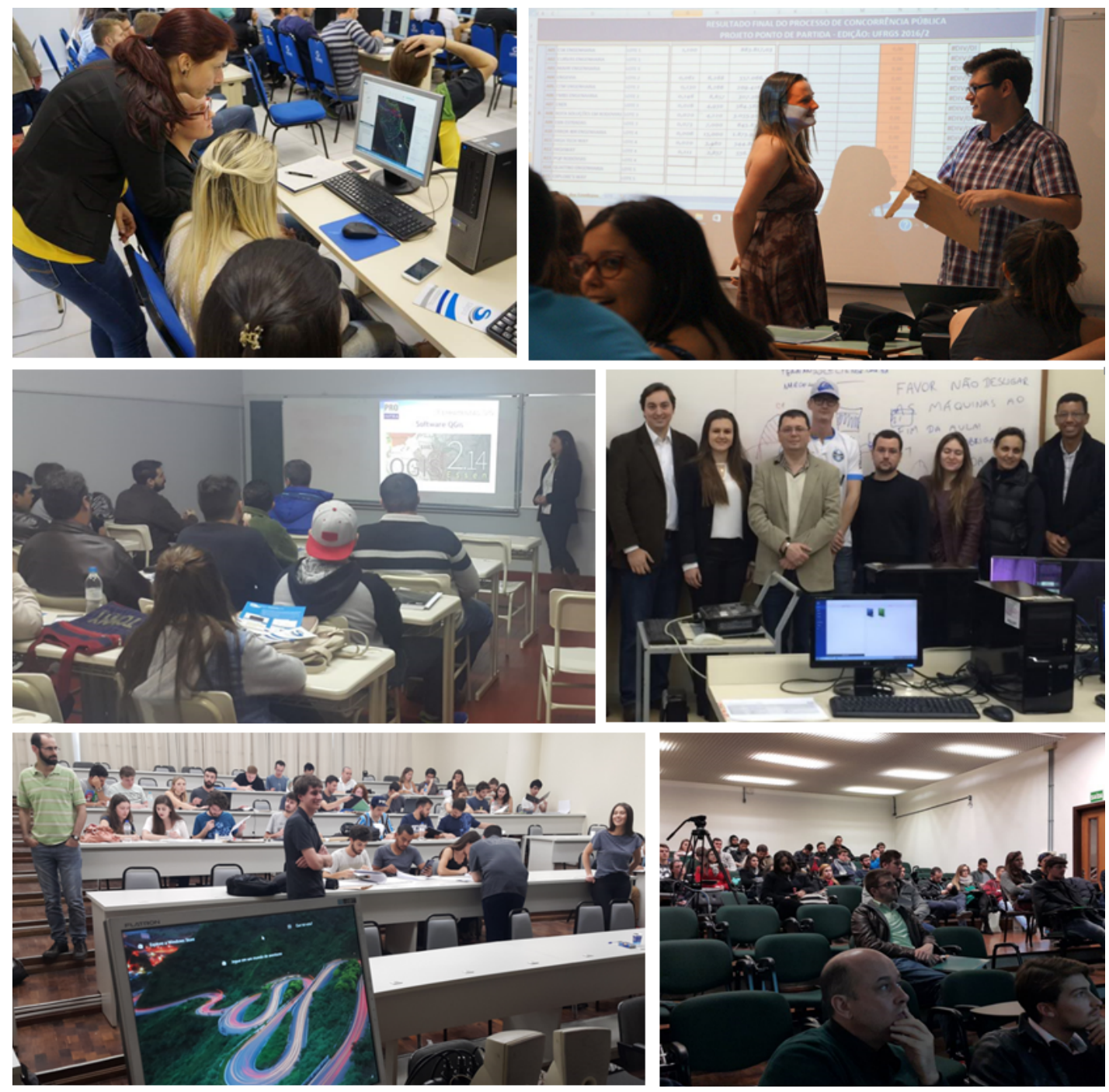

Figura 7: Projeto Ponto de Partida em instituições de ensino superior

Na Pesquisa de Satisfação realizada com os alunos pode-se verificar a importância dada por estes a tal iniciativa. A elevada pontuação recebida nos critérios Lembrar, Compreender e Aplicar indica que a atividade foi reconhecidamente relevante pelos alunos como uma atividade de disseminação de conhecimento. A proposta didática do Projeto também obteve uma expressiva aprovação (Validade), indicando a satisfação dos alunos com o método empregado.

O Projeto Ponto de Partida, além dos conhecimentos e competências técnicas, contribui no desenvolvimento de atributos considerados relevantes, para o profissional de engenharia, pelo mercado de trabalho. A atividade lúdico-real-didático exige dos alunos, em equipes, atitudes como: (i) liderança, (ii) 
comprometimento, (iii) pontualidade. (iv) flexibilidade, (v) tolerância, entre outras. Adicionalmente, incentiva os alunos a se capacitarem em diferentes ferramentas, para realizar as tarefas do Projeto ou atividades extraclasse, transpondo as barreiras do escopo da disciplina.

Para as próximas edições do Projeto, pretende-se acrescentar novos elementos, tais como: (i) Pesquisa de Background; (ii) atividades de avaliações parciais em equipe, em sala de aula; (iii) promoção de atividades colaborativas entre equipes; (iv) obtenção de recursos externos (para custeio do trabalho impresso); (v) premiação para os melhores classificados e o apadrinhamento de entidades beneficentes pelas equipes (incentivando a responsabilidade social). Os elementos adicionais têm como objetivo dar continuidade à evolução promovida por meio do Ciclo PDCA, a partir da análise da Pesquisa de Satisfação, de forma a promover a melhoria contínua do Projeto.

\section{AGRADECIMENTOS}

Os autores agradecem às empresas STE - Serviços Técnicos de Engenharia S.A. e CIENGE - Consultoria em Informática e Engenharia Ltda. pelo apoio no desenvolvimento deste projeto.

\section{REFERÊNCIAS BIBLIOGRÁFICAS}

Belhot, R. V.; Figueiredo, R. S. e Malavé, C. (2001) O Uso da Simulação no Ensino de Engenharia. Anais do XXIX Congresso Brasileiro de Ensino de Engenharia. Porto Alegre.

Bloom, B. S. (1956) Taxonomy of educational objectives: The classification of educational goals. Handbook 1, cognitive domain. New York; Toronto: Longmans, Green. 207 p.

García, D. S. P. e Albano, J. F. (2004) Um relato sobre o ensino de estradas na UFRGS. Anais da IV Semana de Engenharia de Produção e Transportes. Porto Alegre : FEEng.

García. D. S. P.; Wandscheer. M. A.; Santos. F. F. F.; Fraga. P. G. R.; Teixeira. F. G.; d'Azevedo. Z. S. e Di Rado. G. R. (2014) Diretrizes para o desenvolvimento de um sistema avançado para estudos e projetos viários: o conceito BIM no projeto de obras de infraestrutura. PANAM 2014. Santander. Espanha.

Garris, R.; Ahlers, R. e Driskell, J. E. (2002) Games, Motivation, and Learning: A Research and Practice Model. Simulation Gaming, v. 33, n. 4, p. 441-467. DOI: 10.1177/1046878102238607

González, L. A. S.; Morsch, I. B. e Masuero J. R. (2005) Didactic Games in Engineering Teaching - Case: Spaghetti Bridges Design and Building Contest. 18th International Congress of Mechanical Engineering. Ouro Preto.

Goulart, I. B. (2004) Psicologia da Educação: fundamentos teóricos, aplicações à prática pedagógica. 12 ed. Petrópolis: Vozes. $200 \mathrm{p}$.

Keller, J. M. (1983) Motivational Design of Instruction. In: Reigeluth, C. M. Instructional Design Theories and Models. An Overview of their Current Status. New Jersey: Lawrence Earlbaum Associates Hillsdale.

Keller, J. M. (2009) Motivational Design for Learning and Performance: The ARCS Model Approach. Springer. DOI: 10.1007/9781-4419-1250-3

Kirkpatrick, D. L. (1994) Evaluating Training Programs - The Four Levels. Berrett-Koehler Publishers, Inc..

Kirkpatrick, D. L. e J. D. (2007) Implementing the Four Levels. Berrett-Koehler Publ., Inc., San Francisco, CA.

Krueger, R. A. e Casey, M. A. (2014) Focus Groups: A Practical Guide for Applied Research. SAGE Publications.

Macedo, L. (2002) Ensaios construtivistas. 5 ed. São Paulo: Casa do Psicólogo. 170 p.

Moretto, V. P. (2006) Construtivismo: a produção do conhecimento em aula. 4 ed. Rio de Janeiro. DP\&A. 128p.

Morgan D. L. (1996) Focus group. Annual Review of Sociology, v. 22, p. 129-152.

Ozelkan E. e Galambosi, A. (2007) Lampshade game for teaching lean manufacturing. American Society for Engineering Education. Electronic Proceedings.

Prensky, M. (2001) Digital game-based learning. New York: McGraw-Hill.

Sacks, R.; Esquenazi, A. e Goldin, M. (2007) Leapcon: Simulation of lean construction of high-rise apartment buildings. Journal of Construction engineering and management. DOI: 10.1061/(ASCE)0733-9364(2007)133:7(529)

Savi, R. e Ulbricht, V. R. (2008) Jogos Digitais Educacionais: Benefícios e Desafios. RENOTE - Revista Novas Tecnologias na Educação, v. 6, p. 1-10.

Schoemaker, P. J. H. (1995) Scenario Planning: a tool for strategic thinking. Sloan Management Review/Winter, v. 36, n. 2, p. 2540.

Walasek, T.A.; Kucharczyk Z. e D.Morawska-Walasek (2011) Assuring quality of an e-learning project through the PDCA approach. Archives of Materials Science and Engineering, v. 48, n. 1, p. 56-61.

Takatalo, J.; Häkkinen, J.; Kaistinen, J. e Nyman, G. (2010) Presence, Involvement, and Flow in Digital Games. In: Bernhaupt, R. Evaluating User Experience in Games: Concepts and Methods. Springer, p, 23-46.

Van der Heijden, K. (1996) Cenários, a arte da conversação estratégica. Porto Alegre: Bookman. 